\title{
Vitamin E slows down the progression of osteoarthritis (Review)
}

\author{
XI LI, ZHONGLI DONG, FUHOU ZHANG，JUNJIE DONG and YUAN ZHANG \\ Department of Orthopaedic Surgery, First Affiliated Hospital of Kunming Medical University, \\ Kunming, Yunnan 650032, P.R. China
}

Received January 16, 2015; Accepted April 11, 2016

DOI: $10.3892 /$ etm.2016.3322

\begin{abstract}
Osteoarthritis is a chronic degenerative joint disorder with the characteristics of articular cartilage destruction, subchondral bone alterations and synovitis. Clinical signs and symptoms of osteoarthritis include pain, stiffness, restricted motion and crepitus. It is the major cause of joint dysfunction in developed nations and has enormous social and economic consequences. Current treatments focus on symptomatic relief, however, they lack efficacy in controlling the progression of this disease, which is a leading cause of disability. Vitamin $\mathrm{E}$ is safe to use and may delay the progression of osteoarthritis by acting on several aspects of the disease. In this review, how vitamin $\mathrm{E}$ may promote the maintenance of skeletal muscle and the regulation of nucleic acid metabolism to delay osteoarthritis progression is explored. In addition, how vitamin $\mathrm{E}$ may maintain the function of sex organs and the stability of mast cells, thus conferring a greater resistance to the underlying disease process is also discussed. Finally, the protective effect of vitamin E on the subchondral vascular system, which decreases the reactive remodeling in osteoarthritis, is reviewed.
\end{abstract}

\section{Contents}

1. Introduction

2. Vitamin E maintains skeletal muscle which may slow down the rate of joint degeneration

3. Vitamin $\mathrm{E}$ has a gene regulatory function that may delay the development of osteoarthritis

4. Vitamin E maintains sex organ functions which may delay the progression of osteoarthritis

6. Vitamin E regulates mast cell stability which may reduce inflammation associated with osteoarthritis

Correspondence to: Dr Yuan Zhang, Department of Orthopaedic Surgery, First Affiliated Hospital of Kunming Medical University, 4 No. 1 Inpatient Building 295 Xichang Road, Kunming, Yunnan 650032, P.R. China

E-mail: zhhyya@163.com

Key words: osteoarthritis, vitamin E, skeletal muscle, nucleic acid metabolism, mast cell, subchondral vascular system
7. Vitamin E protects the subchondral vascular system which may reduce the necrosis and remodeling of osteoarthritis

8. Conclusion

\section{Introduction}

Osteoarthritis is a commonly occurring disease, with the clinical manifestations of joint pain, swelling and progressive loss of function (Fig. 1). Osteoarthritis increases in prevalence with age and is estimated that $40 \%$ of people $>70$ years old are affected by this disease (1). Synovial inflammation is associated with a number of the signs and symptoms of osteoarthritis, including joint swelling and effusion (2). This multifactorial disease is characterized by destruction of the articular cartilage and subchondral bone alterations (3). The degeneration of the joints is a major cause of disability, which reduces the quality of life. Clinically speaking, degeneration particularly affects the large weight-bearing joints of the legs, namely the hips and knees, but can potentially affect any joint of the body, including the hands and spine $(4,5)$. The manifestations of the disease can vary in severity, but the majority of patients do not require major interventions and receive only intermittent symptom relief. However, in certain patients, the disease progresses rapidly, leading to disability and ultimately joint replacement (6). Current treatments for osteoarthritis, such as non-steroidal anti-inflammatory drugs, are administered to provide symptomatic relief but lack efficacy in controlling the progression of the disease $(7,8)$.

Vitamin $\mathrm{E}$ has various biological functions that have been attributed to its ability to protect an organism against the damaging effects of free radicals by acting as a lipid-based radical chain reaction terminator (9). Vitamin $\mathrm{E}$ is a fat-soluble, water-insoluble, light yellow oil, that is stable to heat and acids, but rather unstable under alkali conditions, in which it is slowly oxidized. It can be found in the nonsaponifiable fractions of vegetable oils and plays various important roles, for example, as an antioxidant and anti-apoptotic agent, in numerous physiological and pathological conditions (10). Various theories on the pathology of osteoarthritis are being investigated that may lead to new therapeutic options. These relate to the role of skeletal muscle (11-14), the effect of nucleic acid metabolism $(15,16)$, sex gland functions (17-19), the action of stable mast cells $(20,21)$ and the importance of the subchondral vascular system $(9,22,23)$ in osteoarthritis and its progression. In the present review, the possibility that vitamin $\mathrm{E}$ may be 
able to delay the progression of osteoarthritis was explored through studying the potential role of this nutritional factor in each of these mechanisms. The association between the antioxidation effect (24) of vitamin E and these mechanisms in osteoarthritis (25) is also explored.

\section{Vitamin E maintains skeletal muscle which may slow down the rate of joint degeneration}

Vitamin $\mathrm{E}$ is essential for the structural and functional maintenance of skeletal muscle $(11,12)$. A study by Chang et al indicated that vitamin $\mathrm{E}$ influences the training-induced adaptation of glutathione peroxidase (GPX) and superoxide dismutase (SOD) activities in rat skeletal muscle (11); in rats, the deprivation of vitamin $\mathrm{E}$ increased the exercise-induced elevation in GPX activity and inhibited exercise-induced SOD activity (14). A study conducted by Baumgartner et al showed that mild oxidative stress led to activation of the intrinsic pathway of apoptosis and death in skeletal muscle cells, which was reduced by supplementation of the culture medium with vitamin E (26). The effects of vitamin E on muscle have been suggested to be of greater importance than those on fertility (27). A deficiency of vitamin E causes muscular dystrophy and morphologic changes in various tissues, accompanied by increased oxygen consumption and alterations in chemical composition and functional behavior of the muscle. Creatine elimination then is increased, which is hypothesized to be the result of an inability of the skeletal muscle to utilize creatine (28). A study of joint degeneration in rabbits conducted by Rehan Youssef et al indicated that quadriceps weakness is a risk factor for osteoarthritis through its functional implications on joint loading, and leads to the onset and progression of osteoarthritic changes in the patellofemoral joint (13). The contribution of muscle weakness to joint loading and the progression of osteoarthritis has been confirmed in humans (29).

\section{Vitamin $\mathbf{E}$ has a gene regulatory function that may delay the development of osteoarthritis}

In animals, vitamin E deficiency causes derangement of nucleic acid metabolism $(30,31)$. These results show that serum vitamin $\mathrm{E}$ is a determinant of bone mass through its regulation of osteoclast fusion. Data discussed in a review by Azzi et al support evidence of a gene regulatory function of vitamin E (9); this comprises the observation of an elevated output of the purine metabolite allantoin in vitamin E-deficient rabbits, and changes in the levels of tissue nucleic acids. Hartman et al conducted a study of exercise-induced DNA damage in human subjects using DNA strand breaks in white blood cells as a biomarker (16), and found that supplementation with vitamin $\mathrm{E}$ for 2 weeks was effective in reducing DNA damage after an incremental exercise test to exhaustion. In a study conducted by Baskin et al (32), following 3 days of endurance training in sled dogs, supplementation with vitamin $\mathrm{E}$ and lutein for 1 month was associated with a reduction in oxidative DNA damage, as demonstrated by decreased levels of 7,8-dihydro-8-oxo-2'-deoxyguanosine $(8-\mathrm{OHdG})$ in the plasma, whereas untreated dogs showed an increase in $8-\mathrm{OHdG}$ levels. Various nuclear changes can be observed in tissues that are severely affected by

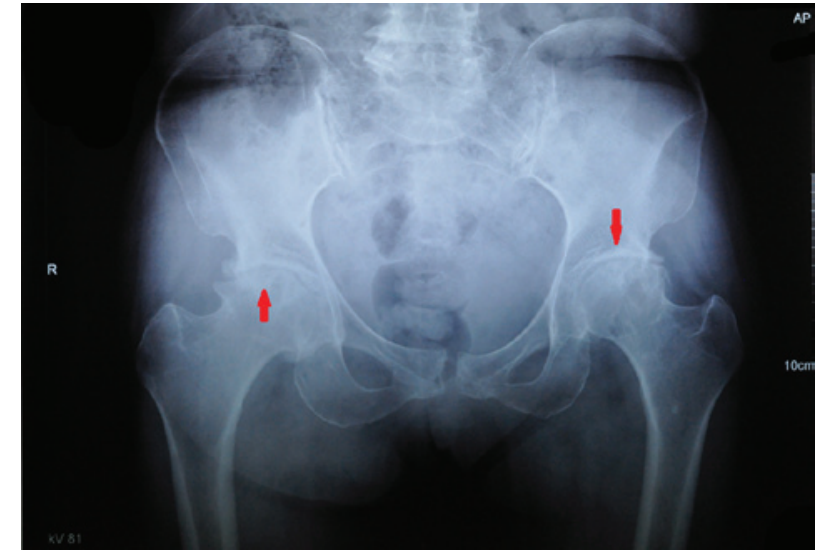

Figure 1. Osteoarthritis of hips. Bone surfaces become less well protected by cartilage, bone may be exposed and damaged. Clinically manifested by joint pain, swelling and progressive loss of function (indicated by arrows).

a deficiency of vitamin E (30). Cell-based assays demonstrated that $\alpha$-tocopherol stimulates osteoclast fusion, independent of its antioxidant capacity, by inducing the expression of dendritic-cell-specific transmembrane protein. This protein is an essential molecule for osteoclast fusion, which occurs via the activation of mitogen-activated protein kinase 14 (p38) and microphthalmia-associated transcription factor, as well as via its direct recruitment to the Tm7sf4 promoter (a gene encoding DC-STAMP) (30). There is a strong hereditary component to osteoarthritis, reflected by high heritability estimates from twin studies (33). Thus, the gene regulatory function of vitamin $\mathrm{E}$ is likely to play an important role in delaying the progression of osteoarthritis. As insights into the molecular mechanisms involved in the initiation and progression of osteoarthritis are gained, certain pathways involved in joint metabolism, including Wnt $/ \beta$-catenin, discoidin domain receptor 2 and proteinase-activated receptor- 2 pathways are being closely examined and their relevance to osteoarthritis evaluated (7).

\section{Vitamin $\mathbf{E}$ maintains sex organ functions which may de- lay the progression of osteoarthritis}

Vitamin E has important effects on the reproductive system. Free radicals and reactive oxygen species, such as hydroxyl radicals, superoxide and hydrogen peroxides, can cause lipid peroxidation (18). Deficiency of vitamin E may lead to damage of the reproductive organs, resulting in conditions such as testicular damage, degenerative spermatogonia and degeneration of the seminiferous tubules (34). A study in goats conducted by Hong et al found that vitamin E supplementation improved the weight of the epididymis, the density and diameters of convoluted seminiferous tubules, spermatogenic cell density and epididymis ductule diameters, particularly when administered at dosages of 80 and 320 IU/day (19). A study conducted by Rao et al to investigate nickel- and/or chromium-induced toxicity in the mouse ovary suggested that vitamin E exerted a protective effect by preventing lipid peroxidation and protecting the antioxidant system (35). Sex organs play a vital role in secretion. Estrogens have been proposed to act as protective factors by certain authors, but as pathogenic 
determinants of osteoarthritis by others (36). While the effects of hormone replacement therapy (HRT) in osteoarthritis appear to be modest, some large observational studies have concluded that when administered over a prolonged period, HRT may exert a beneficial effect on the structural progression of osteoarthritis, particularly in the lower limbs (37).

\section{Vitamin E regulates mast cell stability which may re- duce inflammation associated with osteoarthritis}

Mast cells are a unique type of immune cell that can be activated by various non-immune processes, including acute stress (38), and participate in a variety of inflammatory diseases affecting the skin and joints (39). The role of mast cells in the immune system involves interaction with B and $\mathrm{T}$ cells and the release of mediators (such as IL-4, IL-5 and IL-6) involved in the activation of other cells (such as granulocytes and mast cells) (40). Mast cells are reported to be present in joints (41), and they are suggested to be involved in inflammatory arthritis (42). It has also been reported that mast cells are required for autoimmune arthritis (43). Hyperactivity of mast cells and their uncontrolled accumulation in tissues increases the release of inflammatory mediators contributing to the pathogenesis of several diseases, including arthritis and asthma (40). Natural vitamin E analogs have differing modulatory effects on signal transduction and gene expression in various cell lines; in mast cells, vitamin $\mathrm{E}$ affects protein kinase $\mathrm{C}$, protein phosphatase $2 \mathrm{~A}$ and protein kinase $\mathrm{B}$, which leads to the modulation of proliferation, apoptosis, secretion and migration; therefore, it is possible that, by modulating signal transduction and gene expression, vitamin E prevents diseases with mast cell involvement (21). Mast cell activation is a feature of osteoarthritis, and carboxypeptidase, chymase and tryptase exhibit distinct patterns of release and clearance in the synovial fluid of patients with osteoarthritis (20). The inflammation associated with osteoarthritis may be reduced by vitamin $\mathrm{E}$.

\section{Vitamin E protects the subchondral vascular system which may reduce the necrosis and remodeling of osteo- arthritis}

There is evidence indicating that impaired microvascular blood flow, which may arise due to various combinations of pro-coagulant factors, can result in symptomatic osteoarthritis (44). While the survival of articular chondrocytes depends largely on the diffusion of nutrients from the synovial fluid, the osteocytes in subchondral bone obtain nourishment from a well-developed capillary plexus $(23,45)$. In cases of osteoarthritis, synovial and subchondral vascular engorgement results in necrosis and the gradual remodeling of tissue (46). Vitamin E, along with a network of cellular antioxidant mediators, including catalases and superoxide dismutase, plays a role in the elimination of lipid-soluble free radicals through its action as a free radical scavenger (9). Furthermore, vitamin E is involved in the regulation of certain cellular events, such as the cell cycle progression of vascular smooth muscle cells, the expression of adhesion molecules, the deposition of extracellular matrix and aggregation of platelets (47). In addition, it attenuates capillary endothelial swelling in ischemic and remote muscle (24). It has also been reported that vitamin $\mathrm{E}$ protects vascular walls from damage by limiting cell proliferation, and by assisting in the stabilization of a fibrous cap through its effects on components of the extracellular matrix (48).

\section{Conclusion}

Osteoarthritis is a chronic degenerative joint disorder characterized by destruction of the articular cartilage, subchondral bone alterations and synovitis (1). It is a multifactorial disorder in which ageing, genetic, hormonal and mechanical factors are major contributors to progression (2). Osteoarthritis occurs as a clinical syndrome when these etiological factors result in joint damage of sufficient severity to impair function and produce symptoms. Current treatments are focused on symptomatic relief but they lack efficacy to control the progression of this disease, which is a leading cause of disability.

Vitamin $\mathrm{E}$ is a free radical scavenger, which is able to prevent the oxidation of various readily oxidized substances. The capacity of vitamin E to act as a lipid-based radical chain-breaking agent and thereby to protect against free-radical attack is considered to underlie its effects in the body (49). However, alternative mechanisms of action have also been proposed, particularly gene regulation. Vitamin E has exhibited effects at the mRNA and protein levels, which may be a result of the regulation of gene transcription, mRNA stability, protein translation, protein stability and post-translational events (50). The potential role of vitamin $\mathrm{E}$ in a number of mechanisms is summarized in the present review.

Vitamin E supplementation is safe when appropriate doses are administered (51). In a previous review, Kappus and Diplock summarized the tolerance, toxicological considerations and safety of vitamin E (52). Doses of 100-300 mg/day were concluded to be well tolerated and to cause no side effects. Doses of 200-400 mg/day have been recommended for use in food supplements, under certain conditions, and higher doses of 400-2,000 mg/day do not exhibit side effects in the majority of cases; only at very high doses of $2,150 \mathrm{mg} / \mathrm{day}$ have side effects and intolerance been increasingly noted. To investigate our hypothesis, that vitamin E inhibits the progression of osteoarthritis, clinical studies should be conducted in patients with osteoarthritis to assess the safety of vitamin E supplementation, and to explore the effect of vitamin $\mathrm{E}$ on the progression of osteoarthritis. As an alternative to oral administration, vitamin E could also be administered by intra-articular injection.

The observations summarized in the present review suggest that vitamin E may have a potent therapeutic effect by delaying the progression of osteoarthritis through the maintenance of skeletal muscle, regulation of nucleic acid metabolism, maintenance of sex organ function, stabilization of mast cells and protection of the subchondral vascular system. Vitamin E may be an effective and favorable treatment candidate for osteoarthritis, leading to pain relief in patients.

\section{References}

1. Dieppe PA and Lohmander LS: Pathogenesis and management of pain in osteoarthritis. Lancet 365: 965-973, 2005. 
2. Benito MJ, Veale DJ, FitzGerald O, van den Berg WB and Bresnihan B: Synovial tissue inflammation in early and late osteoarthritis. Ann Rheum Dis 64: 1263-1267, 2005.

3. Goldring MB and Goldring SR: Osteoarthritis. J Cell Physiol 213: 626-634, 2007.

4. Kerkhof HJ, Doherty M, Arden NK, Abramson SB, Attur M, Bos SD, Cooper C, Dennison EM, Doherty SA, Evangelou E, et al: Large-scale meta-analysis of interleukin-1 beta and interleukin-1 receptor antagonist polymorphisms on risk of radiographic hip and knee osteoarthritis and severity of knee osteoarthritis. Osteoarthritis Cartilage 19: 265-271, 2011.

5. Aigner T, Sachse A, Gebhard PM and Roach HI: Osteoarthritis: Pathobiology-targets and ways for therapeutic intervention. Adv Drug Deliv Rev 58: 128-149, 2006.

6. Luyten FP, Tylzanowski P and Lories RJ: Wnt signaling and osteoarthritis. Bone 44: 522-527, 2009.

7. Alcaraz MJ, Megías J, García-Arnandis I, Clérigues V and Guillén MI: New molecular targets for the treatment of osteoarthritis. Biochem Pharmacol 80: 13-21, 2010.

8. Trijau S, Avouac J, Escalas C, Gossec L and Dougados M: Influence of flare design on symptomatic efficacy of non-steroida anti-inflammatory drugs in osteoarthritis: A meta-analysis of randomized placebo-controlled trials. Osteoarthritis Cartilage 18: 1012-1018, 2010

9. Azzi A, Gysin R, Kempná P, Ricciarelli R, Villacorta L, Visarius $\mathrm{T}$ and Zingg $\mathrm{JM}$ : The role of alpha-tocopherol in preventing disease: From epidemiology to molecular events. Mo Aspects Med 24: 325-336, 2003.

10. Bourne N, Wathes DC, Lawrence KE, McGowan M and Laven RA: The effect of parenteral supplementation of vitamin $\mathrm{E}$ with selenium on the health and productivity of dairy cattle in the UK. Vet J 177: 381-387, 2008.

11. Chang CK, Huang HY, Tseng HF, Hsuuw YD and Tso TK: Interaction of vitamin $\mathrm{E}$ and exercise training on oxidative stress and antioxidant enzyme activities in rat skeletal muscles. J Nutr Biochem 18: 39-45, 2007.

12. Nunes VA, Gozzo AJ, Cruz-Silva I, Juliano MA, Viel TA, Godinho RO, Meirelles FV, Sampaio MU, Sampaio CA and Araujo MS: Vitamin E prevents cell death induced by mild oxidative stress in chicken skeletal muscle cells. Comp Biochem Physiol C Toxicol Pharmacol 141: 225-240, 2005.

13. Rehan Youssef A, Longino D, Seerattan R, Leonard T and Herzog W: Muscle weakness causes joint degeneration in rabbits. Osteoarthritis Cartilage 17: 1228-1235, 2009

14. Clavel S, Farout L, Briand M, Briand Y and Jouanel P: Effect of endurance training and/or fish oil supplemented diet on cytoplasmic fatty acid binding protein in rat skeletal muscles and heart. Eur J Appl Physiol 87: 193-201, 2002.

15. Abel K, Reneland R, Kammerer S, Mah S, Hoyal C, Cantor CR Nelson MR and Braun A: Genome-wide SNP association: Identification of susceptibility alleles for osteoarthritis. Autoimmun Rev 5: 258-263, 2006

16. Hartmann A, Niess AM, Grünert-Fuchs M, Poch B and Speit G: Vitamin E prevents exercise-induced DNA damage. Mutat Res 346: 195-202, 1995 .

17. Claassen H, Schicht M and Paulsen F: Impact of sex hormones, insulin, growth factors and peptides on cartilage health and disease. Prog Histochem Cytochem 45: 239-293, 2011.

18. Kilarkaje N,Mousa AM,Al-Bader MM and Khan KM: Antioxidants enhance the recovery of three cycles of bleomycin, etoposide, and cisplatin-induced testicular dysfunction, pituitary-testicular axis, and fertility in rats. Fertil Steril 100: 1151-1159, 2013.

19. Hong Z, Hailing L, Hui M and Guijie Z: Effect of vitamin E supplementation on development of reproductive organs in Boer goat. Anim Reprod Sci 113: 93-101,2009.

20. Nakano S, Mishiro T, Takahara S, Yokoi H, Hamada D, Yukata K, Takata Y, Goto T, Egawa H, Yasuoka S, et al: Distinct expression of mast cell tryptase and protease activated receptor-2 in synovia of rheumatoid arthritis and osteoarthritis. Clin Rheumatol 26: 1284-1292, 2007.

21. Anogeianaki A, Castellani ML, Tripodi D, Toniato E, De Lutiis MA, Conti F, Felaco P, Fulcheri M, Theoharides TC, Galzio R, et al: Vitamins and mast cells. Int J Immunopathol Pharmacol 23: 991-996, 2010.

22. Babarina AV, Möllers U, Bittner K, Vischer $P$ and Bruckner $P$ : Role of the subchondral vascular system in endochondral ossification: Endothelial cell-derived proteinases derepress late cartilage differentiation in vitro. Matrix Biol 20: 205-213, 2001.

23. Kiaer T: Bone perfusion and oxygenation: Animal experiments and clinical observations. Acta Orthop Scand Suppl 257: 1-41, 1994.
24. Dai F, Chen WF and Zhou B: Antioxidant synergism of green tea polyphenols with alpha-tocopherol and L-ascorbic acid in SDS micelles. Biochimie 90: 1499-1505, 2008.

25. Bai B and Li Y. Danshen prevents articular cartilage degeneration via antioxidation in rabbits with osteoarthritis. Osteoarthritis Cartilage 29: 765-773, 2016.

26. Baumgartner HK, Gerasimenko JV, Thorne C, Ashurst LH, Barrow SL, Chvanov MA, Gillies S, Criddle DN, Tepikin AV, Petersen $\mathrm{OH}$, et al: Caspase-8-mediated apoptosis induced by oxidative stress is independent of the intrinsic pathway and dependent on cathepsins. Am J Physiol Gastrointest Liver Physiol 293: G296-G307, 2007.

27. Jukola E, Hakkarainen J, Saloniemi H and Sankari S: Blood selenium, vitamin E, vitamin A and beta-carotene concentrations and udder health, fertility treatments and fertility. J Dairy Sci 79: 838-845, 1996.

28. Aoki MS, Lima WP, Miyabara EH, Gouveia CH and Moriscot AS: Deleterious effects of immobilization upon rat skeletal muscle: Role of creatine supplementation. Clin Nutr 23: 1176-1183, 2004.

29. Shelburne KB, Torry MR and Pandy MG: Contributions of muscles, ligaments and the ground-reaction force to tibiofemoral joint loading during normal gait. J Orthop Res 24: 1983-1990, 2006.

30. Fujita K, Iwasaki M, Ochi H, Fukuda T, Ma C, Miyamoto T, Takitani K, Negishi-Koga T, Sunamura S, Kodama T, et al: Vitamin E decreases bone mass by stimulating osteoclast fusion. Nat Med 18: 589-594, 2012.

31. Özer NK, Negis Y, Aytan N, Villacorta L, Ricciarelli R, Zingg JM and Azzi A: Vitamin E inhibits CD36 scavenger receptor expression in hypercholesterolemic rabbits. Atherosclerosis 184: 15-20, 2006.

32. Baskin CR, Hinchcliff KW, DiSilvestro RA, Reinhart GA, Hayek MG, Chew BP, Burr JR and Swenson RA: Effects of dietary antioxidant supplementation on oxidative damage and resistance to oxidative damage during prolonged exercise in sled dogs. Am J Vet Res 61: 886-891, 2000.

33. Spector TD, Perry LA and Jubb RW: Endogenous sex steroid levels in women with generalised osteoarthritis. Clin Rheumatol 10: 316-319, 1991.

34. Wilson MJ, Kaye D, Smith WE, Quach HT, Sinha AA and Vatassery GT: Effect of vitamin E deficiency on the growth and secretory function of the rat prostatic complex. Exp Mol Pathol 74: 267-275, 2003

35. Rao MV, Chawla SL and Sharma SR: Protective role of vitamin $\mathrm{E}$ on nickel and/or chromium induced oxidative stress in the mouse ovary. Food Chem Toxicol 47: 1368-1371, 2009.

36. Reginster JY, Kvasz A, Bruyere O and Henrotin Y: Is there any rationale for prescribing hormone replacement therapy (HRT) to prevent or to treat osteoarthritis? Osteoarthritis Cartilage 11: 87-91, 2003.

37. Felson DT, Lawrence RC, Dieppe PA, Hirsch R, Helmick CG, Jordan JM, Kington RS, Lane NE, Nevitt MC, Zhang Y, et al: Osteoarthritis: New insights. Part 1: The disease and its risk factors. Ann Intern Med 133: 635-646, 2000.

38. Theoharides TC: Mast cells and stress - a psychoneuroimmunological perspective. J Clin Psychopharmacol 22: 103-108, 2002.

39. Theoharides TC and Cochrane DE: Critical role of mast cells in inflammatory diseases and the effect of acute stress. J Neuroimmunol 146: 1-12, 2004.

40. Zingg JM: Vitamin E and mast cells. Vitam Horm 76: 393-418, 2007.

41. Gotis-Graham I, Smith MD, Parker A and McNeil HP Synovial mast cell responses during clinical improvement in early rheumatoid arthritis. Ann Rheum Dis 57: 664-671, 1998

42. Wooley DE: Mast cells in the rheumatoid lesion-ringleaders or innocent bystanders? Ann Rheum Dis 54: 533-534, 1995.

43. Lee DM, Friend DS, Gurish MF, Benoist C, Mathis D and Brenner MB: Mast cells: A cellular link between autoantibodies and inflammatory arthritis. Science 297: 1689-1692, 2002

44. Corrado A, Neve A and Cantatore FP: Expression of vascular endothelial growth factor in normal, osteoarthritic and osteoporotic osteoblasts. Clin Exp Med 13: 81-84, 2013.

45. Pedersen NW, Kiaer T, Kristensen KD and Starklint H: Intraosseous pressure, oxygenation and histology in arthrosis and osteonecrosis of the hip. Acta Orthop Scand 60: 415-417, 1989.

46. Ghosh P and Smith M: The role of cartilage-derived antigens, pro-coagulant activity and fibrinolysis in the pathogenesis of osteoarthritis. Med Hypotheses 41: 190-194, 1993. 
47. Villacorta L, Azzi A and Zingg JM: Regulatory role of vitamins $\mathrm{E}$ and $\mathrm{C}$ on extracellular matrix components of the vascular system. Mol Aspects Med 28: 507-537, 2007.

48. Chiquet M, Renedo AS, Huber F and Flück M: How do fibroblasts translate mechanical signals into changes in extracellular matrix production?. Matrix Biol 22: 73-80, 2003.

49. Azzi A and Stocker A: Vitamin E: Non-antioxidant roles. Prog Lipid Res 39: 231-255, 2000

50. Ricciarelli R, Zingg JM and Azzi A: Vitamin E 80th anniversary: A double life, not only fighting radicals. IUBMB Life 52: 71-76, 2001.
51. WU J, Karlsson K and Danielsson A: Effects of vitamins E, C and catalase on bromobenzene- and hydrogen peroxide-induced intracellular oxidation and DNA single-strand breakage in Hep G2 cells. J Hepatol 26: 669-677, 1997.

52. Kappus H and Diplock AT: Tolerance and safety of vitamin E: A toxicological position report. Free Radic Biol Med 13: 55-74, 1992. 